\title{
Synergistic effects of three sterol biosynthesis inhibiting fungicides on the toxicity of a pyrethroid and neonicotinoid insecticide to bumble bees
}

\author{
Aaron Iverson ${ }^{1,2}$, Casey $\operatorname{Hale}^{1}$, Leeah Richardson ${ }^{1}$, Olivia Miller ${ }^{1}$, Scott McArT $^{1}$ \\ ${ }^{1}$ Department of Entomology, Cornell University, 4128 Comstock Hall, Ithaca, NY 14853, USA \\ ${ }^{2}$ Department of Environmental Studies, St. Lawrence University, 201 Memorial Hall, Canton, NY 13617, USA
}

Received 13 February 2019 - Revised 29 June 2019 - Accepted 18 July 2019

\begin{abstract}
Understanding how different pesticides influence bee health is inhibited by a limited knowledge about the interactions between different compounds to which bees are simultaneously exposed. Although research has demonstrated synergistic effects of some sterol biosynthesis inhibiting (SBI) fungicides on the toxicity of certain insecticides to bees, a high degree of variability exists in the relatively few SBI fungicide-insecticide interactions tested. Furthermore, most research has been conducted on honey bees, Apis mellifera, limiting our understanding of pesticide synergisms in native wild bees. We tested the effects of the SBI fungicides difenoconazole, myclobutanil, and fenhexamid on acute contact toxicity of the insecticides thiamethoxam (neonicotinoid) and bifenthrin (pyrethroid) to the common eastern bumble bee, Bombus impatiens. Based on range-finding trials, we selected a single dosage of each pesticide, with insecticides approximating LD20 values and fungicides approximating their maximum sublethal levels. We found that the triazole SBI fungicide difenoconazole interacted synergistically with bifenthrin, with a maximum synergy ratio of 1.48 , while the triazole myclobutanil interacted synergistically with both bifenthrin and thiamethoxam, with maximum synergy ratios of 11.0 and 2.38 , respectively. However, the hydroxyanilide SBI fungicide fenhexamid did not exhibit a synergistic effect on either insecticide. Our results suggest that certain SBI fungicides, and potentially those from particular SBI classes, may be particularly harmful to bumble bee health when co-exposure to insecticides occurs, despite their low toxicity when experienced in isolation.
\end{abstract}

\section{bee conservation / bioassay / ecotoxicology / pesticide interactions / wild bee}

\section{INTRODUCTION}

Unprecedented losses of managed western honey bee (Apis mellifera) colonies and parallel declines in wild bee populations in recent years have stimulated a wealth of research on potential causes. While several factors are shown to have

Electronic supplementary material The online version of this article (https://doi.org/10.1007/s13592-019-00681-0) contains supplementary material, which is available to authorized users.

Corresponding author: A. Iverson, aiverson@stlawu.edu

Manuscript editor : Monique Gauthier negative impacts on bee populations, including pathogens, climate change, and habitat loss, agrochemical exposure has surfaced as a major concern, especially in agricultural landscapes (Mullin et al. 2010; Goulson et al. 2015; Koh et al. 2016). While the impacts of general pesticide use on bee populations and the susceptibility of bees to individual pesticides are well studied, less is known about the interactive effects of pesticides on bee health, especially in non-A. mellifera bees (Sanchez-Bayo and Goka 2014; but see Thompson 2012). This knowledge gap is a critical missing link to understanding bee decline, given that bees are commonly exposed to multiple pesticides 
simultaneously when foraging or through contact with hive products where pesticides have accumulated (Schmuck et al. 2003; Johnson et al. 2010; Mullin et al. 2010; David et al. 2016; Fisher et al. 2017).

Some pesticide combinations are particularly dangerous to bees, where synergistic interactions increase their toxicity. For instance, sterol biosynthesis inhibiting (SBI) fungicides (mode of action: sterol biosynthesis in membranes (Fungicide Resistance Action Committee 2019)) have been shown to interact with neonicotinoid and butenolide (mode of action: nicotinic acetylcholine receptor (nAChR) competitive modulators) and pyrethroid (mode of action: sodium channel modulators) (Insecticide Resistance Action Committee 2018) insecticides by inhibiting cytochrome P450monooxygenase activity in bees (Colin and Belzunces 1992; Pillings and Jepson 1993; Schmuck et al. 2003; Iwasa et al. 2004; Biddinger et al. 2013; Johnson et al. 2013; Sgolastra et al. 2016; Raimets et al. 2017; Tosi and Nieh 2019). Cytochrome P450s are a large family of monooxygenases found in many organisms that are important in the detoxification of a wide array of xenobiotics and for membrane synthesis in fungi (Werck-Reichhart and Feyereisen 2000; Črešnar and Petrič 2011). Thus, although SBI fungicides can control fungal pathogens on crops, an unintended consequence to bees is a decrease in their ability to metabolize both naturally occurring plant toxins (Mao et al. 2017) and certain pesticides, such as butenolides, neonicotinoids, and pyrethroids (Glavan and Božič 2013; Gong and Diao 2017; Tosi and Nieh 2019).

Two primary limitations constrain our understanding of the extent to which fungicides may have synergistic effects on insecticides. First, most research on pesticide interactions in bees has been done on A. mellifera (but see Biddinger et al. 2013; Sgolastra et al. 2016; Raimets et al. 2017; Robinson et al. 2017). As wild bees are the primary pollinators of most non-agricultural and many agricultural plants (Garibaldi et al. 2013) and many populations are in decline (Goulson et al. 2015), it is critical to understand how wild bee species respond to potentially synergistic compounds. The limited research that exists on wild bee species shows the potential for a high variability in the response of different bee species to fungicide-insecticide interactions, and that responses observed in A. mellifera cannot reliably be extrapolated to wild bees (Biddinger et al. 2013; Sgolastra et al. 2016). Differential responses among bee species could be expected based on traits such as size and sociality, as well as differential abilities to detoxify xenobiotics. For instance, in single-compound bioassays, the common eastern bumble bee, Bombus impatiens, was found to be approximately seven times less sensitive to contact doses of insecticides than A. mellifera (Sanchez-Bayo and Goka 2014), even though both species are closely related in the family Apidae.

A second limitation to a clearer understanding of fungicide-insecticide interactions is the high variability within a given bee species in the magnitude of synergistic response to different pesticide combinations, even among pesticides from the same pesticide class. For example, Iwasa et al. (2004) found a 17-fold difference in synergism ratios between different SBI fungicides and the neonicotinoid acetamiprid. Given the difficulty in predicting the interactions between these agricultural products, further research is necessary on additional potential synergists to determine which pesticide combinations are most threatening to bees.

In this study, we investigated the interactive effects of two insecticides, a neonicotinoid (thiamethoxam) and a pyrethroid (bifenthrin), and three SBI fungicides, difenoconazole, fenhexamid, and myclobutanil, on the mortality of B. impatiens. We selected these compounds due to their widespread use (United States Geological Survey 2017) and the potential risk to pollinator health based on other studies using chemicals of the same fungicide and insecticide modes of action (Colin and Belzunces 1992; Pillings and Jepson 1993; Schmuck et al. 2003; Iwasa et al. 2004; Biddinger et al. 2013; Johnson et al. 2013; Sgolastra et al. 2016; Raimets et al. 2017). Although the interactive effects of these chosen chemicals are largely unknown, the fungicides pose a relatively low acute risk (all honey bee contact LD50s $>40 \mu \mathrm{g}$ bee $^{-1}$ ) when applied alone, whereas the insecticides pose a high acute risk (honey bee contact LD50 of 0.015 and $0.025 \mu \mathrm{g} \mathrm{bee}{ }^{-1}$ for bifenthrin and thiamethoxam, 
respectively) (Sanchez-Bayo and Goka 2014). We hypothesized that we would observe differential synergistic effects on $B$. impatiens mortality depending on the class of insecticide and fungicide tested.

\section{MATERIALS AND METHODS}

\subsection{Hive acquisition and maintenance}

We acquired ten total Natupol Excel $B$. impatiens hives from Koppert Biological Systems (Howell, MI, USA) in February, April, and July 2018. Hives consisted of 75-100 workers, a laying queen, and brood upon delivery. The hives were stored at approx. $22^{\circ} \mathrm{C}$ and were kept in their original cardboard boxes, which provided minimal light exposure. We provided bees with continual access to $30 \%(w / v)$ sucrose solution (Masi Biller et al. 2015; Richardson et al. 2015) through bottom-access bladders that came with the hives. Twice weekly, we provided the bees with pollen balls $(\sim 5 \mathrm{~g})$ made from a mixture of ground "High Desert" pollen granules (CC Pollen Inc.; Phoenix, AZ, USA) removed from honey bee corbicula and $30 \%(w / v)$ sucrose solution. To confirm there were little to no pesticides in the pollen, we screened a sample of the pollen granules for 267 pesticides using liquid chromatography/mass spectrometry (LC-MS/MS) using the methods outlined by Urbanowicz et al. (2019).

We detected only one pesticide, the acaricide coumaphos, at a level below the limit of quantification $(<0.525 \mathrm{ng} / \mathrm{g})$. We used bees from each colony in the bioassays until the colony failed to produce sufficient numbers of new workers (approx. 6-9 weeks after acquisition). Colonies that had any visual signs of pathogen infection (e.g., deformed wing virus) were not used in the bioassays. Some research indicates that bee susceptibility to pesticides is dependent on the season of the year, which could have implications for differential susceptibility of a bumble bee colony throughout its lifecycle (Tosi and Nieh 2019). We attempted to limit any potential colony age effects by discarding colonies as soon as they showed signs of decreasing vigor and by varying when we tested the different trials of each pesticide combination.

\subsection{Worker selection}

After initial acquisition of the hives, all workers were marked on the top of the thorax using a white oil-based paint pen (Sharpie; Oak Brook, IL, USA). This paint application was found to have no impact on mortality in separate trials (using 15 control bees and 15 treatment bees) designed to test any adverse impacts of the paint (S. McArt, unpublished data). To mark the bees, we first removed the queen from the hive and anesthetized the remaining workers with $\mathrm{CO}_{2}$ for $<2 \mathrm{~min}$ (Pillings and Jepson 1993; Thompson et al. 2014). We then removed workers from the hive and marked them in a dark room under red light. In order to avoid effects of individual bee age on mortality, only unmarked workers that had eclosed within 5 days were selected for bioassay trials. We also excluded workers that had recently eclosed $(\sim<24 \mathrm{~h})$, which we identified based on the light color of the hairs. As B. impatiens workers vary considerably in size, it was not possible to ensure that all workers used in the bioassays were the same size. However, we excluded the largest (approx. >90 mg dry weight) and smallest (approx. $<12 \mathrm{mg}$ dry weight) bees from trials and distributed the remaining sizes evenly across treatments from a given colony on a given date. Since all treatments for a given trial were conducted on a given date, this protocol ensured that similar-sized bees were represented in each treatment and any variation in size simply contributed to variation in the trials. From a subset of bees used across all experimental groups (chemical combinations) in the bioassays, the average bee dry mass was $41.76 \mathrm{mg}( \pm 1.41 \mathrm{SE})$ and did not differ significantly $(p>0.05)$ among the combinations (Online Resource 1).

\subsection{Pesticide selection and doses}

We tested the effects of three fungicides and two insecticides singly and in all fungicide by insecticide combinations on B. impatiens mortality. For insecticides, we used thiamethoxam, a neonicotinoid, and bifenthrin, a pyrethroid. We selected three SBI fungicides: difenoconazole and myclobutanil (SBI class I: triazoles) and fenhexamid (SBI class III: hydroxyanilide) 
(Fungicide Resistance Action Committee 2019). These pesticides were selected based on them spanning a diversity of compounds that could be potential synergists and being commonly applied in agriculture across the USA (United States Geological Survey 2017). Most studies on SBI fungicides have investigated interactions moderated by SBI fungicides of the triazole chemical group (Colin and Belzunces 1992; Pillings and Jepson 1993; Schmuck et al. 2003; Iwasa et al. 2004; Biddinger et al. 2013; Johnson et al. 2013; Sgolastra et al. 2016; Raimets et al. 2017; Tosi and Nieh 2019). Therefore, we selected fenhexamid because of its growing use in agriculture and the lack of studies that have researched interactions with pesticides from the hydroxyanilide chemical group within the SBI fungicide class (Fungicide Resistance Action Committee 2019). Bifenthrin was obtained from ChemService, Inc. (West Chester, PA, USA), while all other pesticides were obtained from Sigma-Aldrich (St. Louis, MO, USA) as Pestanal analytical standards.

To select pesticide doses, we used published contact LD50 values for honey bees (Tomlin 2009; Sanchez-Bayo and Goka 2014) and our own range-finding trials to attain the approximate LD20 (over $48 \mathrm{~h}$ ) for the insecticides and the maximum sublethal dose that was soluble in acetone for the fungicides. During each range-finding trial, selected workers were treated with a range of five doses of a particular pesticide and acetone in order to find the dose of the pesticide that corresponded with the desired level of mortality. If the tested range was not adequate, we followed with another test of adjusted range. The maximum soluble sublethal dose of each fungicide was defined as the maximum dose that was soluble in acetone and that did not cause increased mortality compared with the control treatment. The three selected fungicides all had low toxicities to $B$. impatiens when applied individually and we did not observe higher mortality than controls in any of our range-finding trials, which reached the limit of the fungicides' solubility. Therefore, we used concentrations of the fungicides that approached the maximum solubility of the compound in acetone. Based on these criteria, we used the following contact doses per bee in the bioassays: thiamethoxam $(0.024 \mu \mathrm{g})$, bifenthrin
$(0.255 \mu \mathrm{g})$, difenoconazole $(200 \mu \mathrm{g})$, fenhexamid $(250 \mu \mathrm{g})$, and myclobutanil $(400 \mu \mathrm{g})$, each of which were dissolved in acetone.

\subsection{Treatments and dosing methods}

Each bioassay consisted of four treatments to assess acute contact toxicity to $B$. impatiens: acetone control, fungicide alone, insecticide alone, and both the fungicide and insecticide applied together. To dose individual bees, we first anesthetized them in a small container with $\mathrm{CO}_{2}$ for $10 \mathrm{~s}$. We then applied two separate $1 \mu \mathrm{L}$ doses (total of $2 \mu \mathrm{L}$ per bee) of acetone or acetone-pesticide solution, applied $1 \mathrm{~h}$ apart, to each bee in all trials. The first dose was applied on the prothorax and the second dose was applied on the dorsal side of the abdomen to avoid direct interactions between the chemicals that could confound results. Control bees received $1 \mu \mathrm{L}$ of acetone in both doses; the insecticide treatment group received acetone in the first dose, followed by the insecticide solution; the fungicide treatment group received the fungicide solution in the first dose, followed by acetone; the combination treatment received the fungicide solution in the first dose followed by the insecticide solution. We left the bees in containers separated by treatment during the 1 - $\mathrm{h}$ waiting period in between dose applications, and we anesthetized them again in the same way as above prior to the second dosing.

Following the second dosing, we placed bees in $16 \mathrm{~cm} \times 16 \mathrm{~cm} \times 10 \mathrm{~cm}$ plastic cages separated by treatment. Each cage had an average of 8.30 ( \pm $0.41 \mathrm{SE}$ ) bees, and this number was consistent across treatments within a trial. The exact numbers of bees used in each cage were a function of the number of bees of the appropriate age (unmarked) that were available at each trial start time. Each cage had a $20-\mathrm{mL}$ syringe filled with $30 \%(w / v)$ sucrose solution from which the bees could feed ad libitum. No cage ever completely depleted this supply of sucrose; therefore, it was not replaced for the duration of the trial (maximum 3 days). We conducted the dosing experiments between March and August 2018, and we assessed mortality at 24,48 , and 72 h posttreatment. 


\subsection{Statistical analyses}

We plotted survival curves for each fungicide-insecticide combination and tested for statistically significant synergistic interactions between the pesticides using a modified binomial proportion test for additivity (BPA) (Hainzl and Casida 1996; Sgolastra et al. 2016; Raimets et al. 2017). This test compares observed mortalities with expected mortalities resulting from additive effects according to the Bliss independence criterion, which states that the expected additive mortality of two compounds is the sum of the mortality of each compound minus the product of the mortality of the two compounds (Greco et al. 1995). We calculated synergism ratios at each time step by dividing the observed mortality by the expected mortality based on additivity (per the Bliss independence criterion), where values $>1$ indicate a potential (though not necessarily statistically significant) synergism. We performed the BPA test at each time step where mortality data were recorded $(24 \mathrm{~h}, 48 \mathrm{~h}, 72 \mathrm{~h})$ for each fungicide-insecticide combination trial, and we corrected for multiple comparisons using the Bonferonni-Holm correction (Holm 1979).

Sample sizes differed between the different combinations of pesticides tested; therefore, to ensure that statistical significance was not affected by sample size, we performed a power analysis for two proportions (Cohen 1988). Here, we calculated the sample size necessary to detect a statistically significant difference $(p<0.05)$ between the expected additive mortality and the observed mortality of the fungicide-insecticide treatment using the recommended power (0.8) and effect size calculations for proportion data (Cohen 1988). Power analyses and graphical presentation (survival curves) were conducted in $\mathrm{R}$ version 3.5.0 ( $\mathrm{R}$ Core Team 2018) using the package "pwr" (Champely 2018) and "survminer" (Kassambara and Kosinski 2018), respectively. The BPA test, including the Bonferonni-Holm correction, was conducted in $\mathrm{R}$ version 3.5.0 ( $\mathrm{R}$ Core Team 2018) based on a script provided in Sgolastra et al. (2016).

\section{RESULTS}

We detected statistically significant synergistic interactions in bioassays with bifenthrin crossed with difenoconazole and myclobutanil, as well as with thiamethoxam crossed with myclobutanil (Figures 1 and 2). The bifenthrin-myclobutanil interaction was the most synergistic, where the combination treatment exhibited statistically higher mortality than the expected value at all time steps (BPA test at $24 \mathrm{~h}, 48 \mathrm{~h}$, and $72 \mathrm{~h}, p<0.001$ ), with synergism ratios of $2.56,3.28$, and 11.0 at each of the time steps, respectively (Figure 2). The only synergistic interaction observed with thiamethoxam was in the trials with myclobutanil at $24 \mathrm{~h}$ (BPA test, $p<0.01$ ), where a synergism ratio of 2.38 was detected. In the bifenthrindifenoconazole trial, we also observed a synergistic interaction at $48 \mathrm{~h}$ and $72 \mathrm{~h}$ (BPA test, $p<$ $0.05)$, although synergism ratios were low, at 1.48 and 1.37 , respectively. Neither bifenthrin nor thiamethoxam interacted synergistically with the fungicide fenhexamid. Mortality in the fungicide treatments was consistently similar to the mortality in the control treatments for all pesticide combinations, indicating an overall low toxicity of fungicides when applied alone. Power analyses indicated that results would not change for trials that did not show statistically significant synergistic interactions had we used sample sizes that were all equal to the largest sample size $(N=60$; Online Resource 2).

\section{DISCUSSION/CONCLUSION}

We show that some SBI fungicides interact synergistically with the neonicotinoid thiamethoxam or the pyrethroid bifenthrin to increase $B$. impatiens mortality, thus adding to the growing literature on SBI-mediated pesticide synergisms and providing new evidence for impacts on $B$. impatiens a wild bee native to North America. We found that both the occurrence and strength of a synergistic interaction with a given insecticide differed depending on the specific fungicide, despite all the fungicides having the same mode of action. The fungicides difenoconazole and myclobutanil synergistically interacted with the pyrethroid 

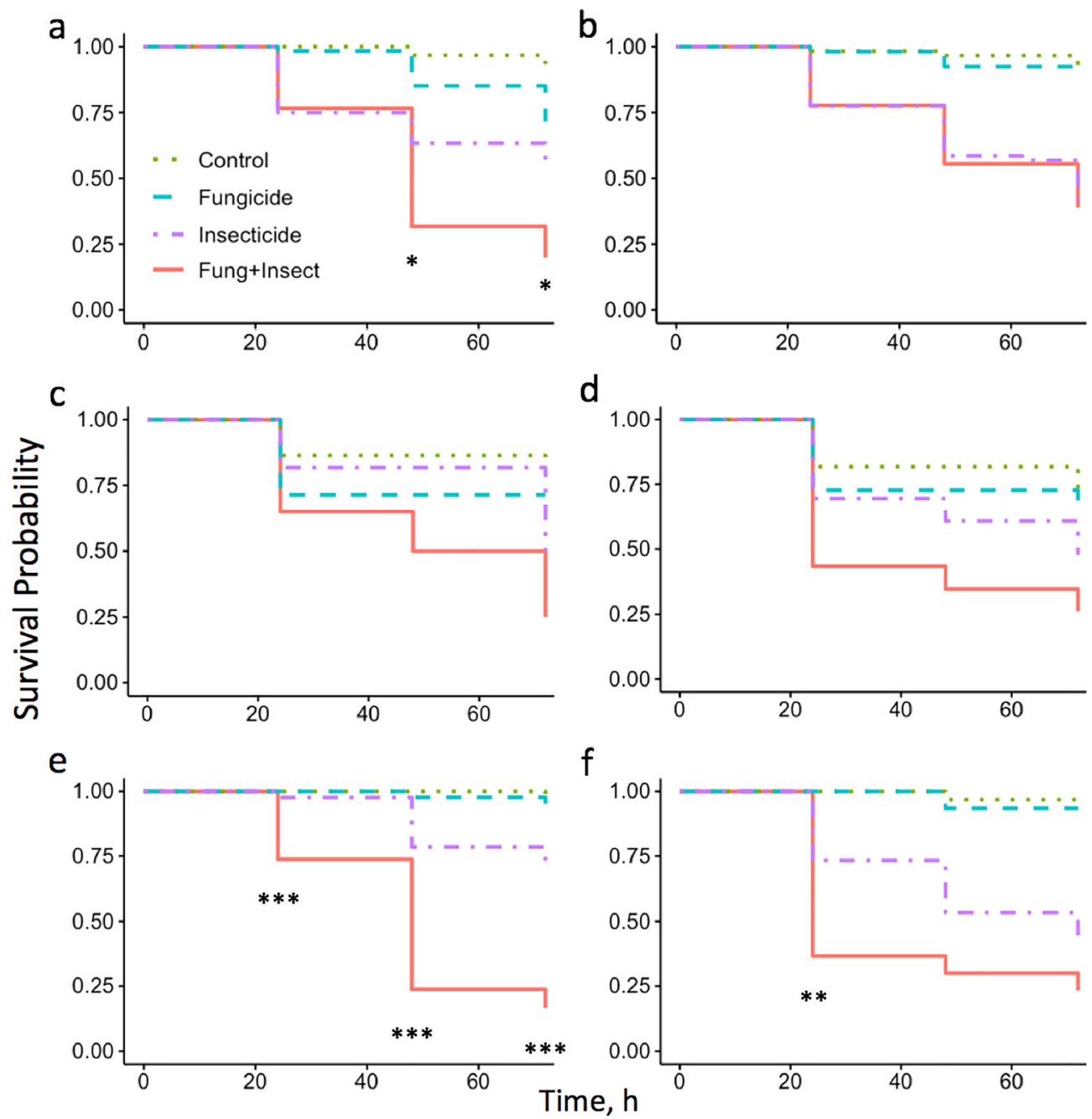

Figure 1. Survival curves for B. impatiens in each fungicide-insecticide combination, including treatments of solvent control, fungicide alone, insecticide alone, and fungicide-insecticide combined. a Bifenthrin-difenoconazole (N: C (control), F (fungicide), I (insecticide), B (both) $=60$ ). b Thiamethoxam-difenoconazole $(\mathrm{N}: \mathrm{C}=58, \mathrm{~F}=53$, $\mathrm{I}=58, \mathrm{~B}=54)$. $\mathbf{c}$ Bifenthrin-fenhexamid $(\mathrm{N}: \mathrm{C}=22, \mathrm{~F}=21, \mathrm{I}=22, \mathrm{~B}=20)$. $\mathbf{d}$ Thiamethoxam-fenhexamid $(\mathrm{N}: \mathrm{C}=$ 22, $F=22, I=23, B=23)$. e Bifenthrin-myclobutanil ( $N: C, F, I, B=42)$. f Thiamethoxam-myclobutanil $(\mathrm{N}: \mathrm{C}=$ $31, F=31, I=30, B=30$ ). Statistically synergistic effects are indicated according to a modified binomial proportion test for additivity (BPA); $* p<0.05, * * p<0.01, * * * p<0.001$

bifenthrin, while myclobutanil synergistically interacted with the neonicotinoid thiamethoxam, to increase contact toxicity to $B$. impatiens . Contrastingly, the fungicide fenhexamid did not demonstrate a synergistic effect on either insecticide. These results highlight the importance of considering interactive effects in pesticide risk assessment for bees.
Our findings are consistent with other studies that show variable synergistic effects of SBI fungicides on the toxicity of neonicotinoids and pyrethroids, where the strength of synergy depends on the specific pesticide combination tested even within the same pesticide class (Iwasa et al. 2004; Johnson et al. 2010; Thompson et al. 2014). We provide new evidence for these effects 
a $1.0 \cdot 24 \mathrm{~h}$

0.8 .

0.6 .

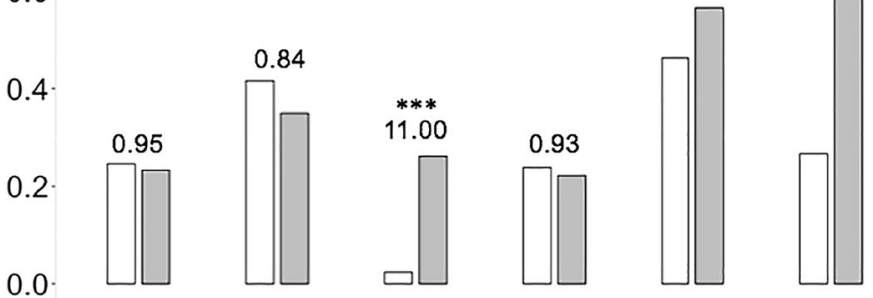

b $1.0 \cdot 48 \mathrm{~h}$

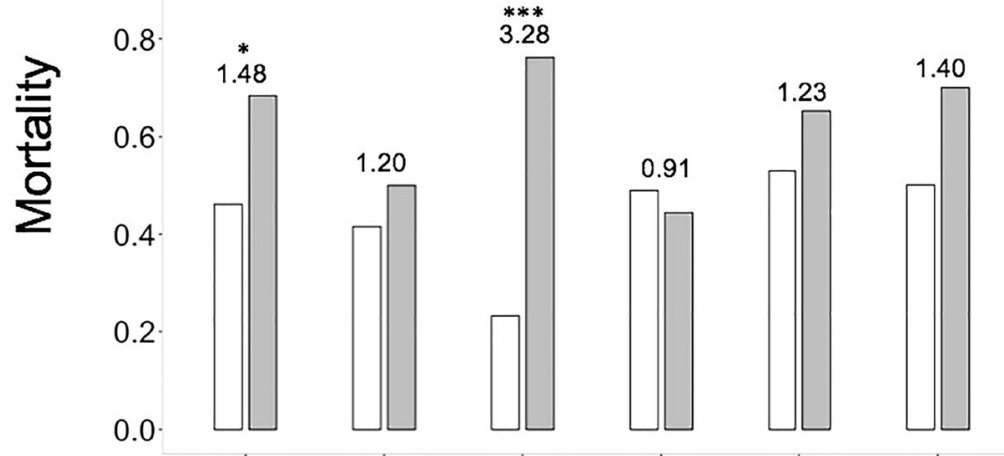

C $1.0 \cdot 72 \mathrm{~h}$

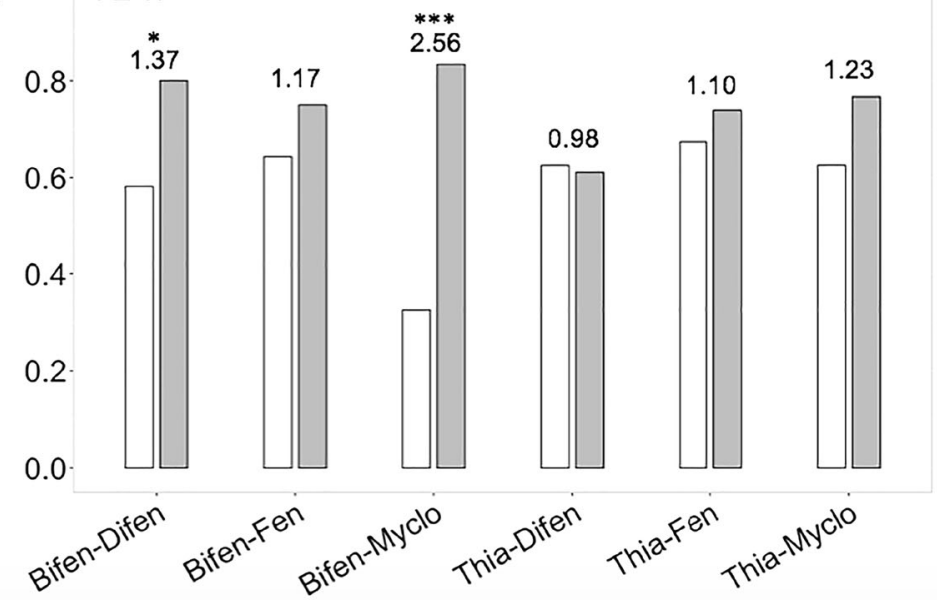

Figure 2. Mortality of $B$. impatiens in each fungicide-insecticide combination experiment at a $24 \mathrm{~h}, \mathbf{b} 48 \mathrm{~h}$, and c $72 \mathrm{~h}$. Open bars: expected additive mortality based on separate insecticide and fungicide treatments according to the Bliss independence criterion; closed bars: observed mortality. Values above bars indicate the synergism ratio (observed mortality/expected mortality. Statistically significant results are reported for synergies according to the modified binomial proportion test for additivity; ${ }^{*} p<0.05$, ** $p<0.01$, ***p $<0.001$. 
as, with the exception of one study that evaluated thiamethoxam and myclobutanil in honey bees (Thompson et al. 2014), the specific pesticide combinations we tested had not previously been analyzed for their synergistic toxicity on any bee species.

Although we observed relatively stronger synergistic effects with bifenthrin than with thiamethoxam (e.g., maximum synergy of 11.0 with myclobutanil and bifenthrin compared with 2.38 with myclobutanil and thiamethoxam), there is little evidence to suggest that pyrethroids in general would be more synergistic than neonicotinoids, as the strength of interaction is highly dependent on the specific chemical tested and a high amount of variability exists even within the same insecticide class. For example, the mortality of A. mellifera treated with one of five SBI fungicides in combination with the pyrethroid taufluvalinate varied between 0.65 and 74.2 -fold, depending on the dosage, compared with control mortality (Johnson et al. 2013). Similarly, in A. mellifera, Iwasa et al. (2004) show the nitrosubstituted neonicotinoid imidacloprid to have small synergism ratios of 1.52 and 1.85 when crossed with two SBI fungicides, while the cyano-substituted neonicotinoids acetamiprid and thiacloprid had large synergy ratios as high as 244 and 1141, respectively, when crossed with the same fungicides. The relatively small interactive effects we observed with all three fungicides on thiamethoxam may be due to the latter being a nitro-substituted neonicotinoid, where we may have observed stronger effects if we had tested a cyano-substituted neonicotinoid.

The differences in synergistic effects that we observed among the three SBI fungicides may reflect their distinct chemical classes within the same SBI mode of action group. Fenhexamid, which did not show synergisms with either insecticide, belongs to a different class of SBI fungicides (class III, hydroxyanilide) than difenoconazole and myclobutanil (class I, triazole) (Fungicide Resistance Action Committee 2019). These differences may reflect variability in how the classes inhibit the P450 enzymes, thereby having differential effects on P450 inhibition. Fenhexamid, and potentially other fungicides within the hydroxyanilide class, may therefore offer an improvement over triazole fungicides in terms of pesticide risk to bees.

There is some evidence that the synergies we observed were strongest in the early stages of our bioassays and decreased over time, as was the case in the trial of myclobutanil + bifenthrin (synergy of 11.0 at $24 \mathrm{~h}$ and 2.56 at $72 \mathrm{~h}$ ) and myclobutanil + thiamethoxam (synergy of 2.38 at $24 \mathrm{~h}$ and no synergies at $48 \mathrm{~h}$ or $72 \mathrm{~h}$ ). These results concur with other studies showing decreasing synergism ratios through time (Sgolastra et al. 2016; Raimets 2017), and may reflect how the most susceptible bees can only die once. In contrast, for the trial of difenoconazole + bifenthrin, we observed a synergy at $24 \mathrm{~h}$, but not at the latter time points. However, the synergies observed in this trial were relatively weak (1.48 and 1.37 at $48 \mathrm{~h}$ and $72 \mathrm{~h}$, respectively); therefore, the overall magnitude of change in mortality across all time points was not as pronounced as it was in the abovementioned synergistic combinations.

The sole fungicide-insecticide interaction common to our study and any other study, to the best of our knowledge, was thiamethoxam and myclobutanil (Thompson et al. 2014). Here, the mild synergy we observed in $B$. impatiens (mean synergism ratio of 1.67 ) concurs with those found in A. mellifera (synergism ratio of 1.27). However, we did not use the same doses as those in Thompson et al. (2014), since synergism ratios can be strongly affected by the dose of the pesticide (Johnson et al. 2013; Thompson et al. 2014); our observed synergism ratios may not have been as similar had we used the same dose. We are unaware of other research testing bifenthrin in combination with any SBI fungicide, although some studies have observed variable and sometimes large synergistic effects of myclobutanil on the toxicity of other pyrethroids on A. mellifera (Pillings and Jepson 1993; Johnson et al. 2013).

Although fungicides have generally been considered to be a low risk to bees, evidence is mounting that fungicides may be riskier than previously thought. For instance, the amount of fungicides applied on apple orchards in New York, USA strongly influenced bee diversity and abundance (Park et al. 2015), and the quantity of certain fungicides sprayed in the surrounding 
landscape was the most important factor for predicting bumble bee range contraction across the USA (McArt et al. 2017b). Synergistic interactions between fungicides and insecticides mediated by cytochrome P450 inhibition could be one mechanism that explains the surprisingly detrimental effects of fungicides, especially given the high probability for bees to be exposed to potentially interacting pesticides. For example, in one study, $82 \%$ of $A$. mellifera colonies had combinations of pesticides that are known to interact synergistically (Mullen et al. 2017). There is also evidence that some fungicides increase a bee's susceptibility to parasites (Pettis et al. 2012, 2013), potentially by altering the microbiome (Kakumanu et al. 2016) or midgut cell function (Huang et al. 2013). Therefore, it is possible that a combination of these threats posed by fungicides may be interacting to negatively affect bee health.

\subsection{Limitations}

The mortality we observed in the control treatments and in the treatments of a given insecticide varied across trials, likely due to differences in the age or general health of the source colony. We did not use colonies that had any visual signs of pathogen infection; however, some colonies may have been affected by pathogens that do not show obvious phenotypes. We controlled for these potential colony-specific impacts on mortality within a given trial by using bees from the same colonies across all treatments within each trial and by varying the timing (in relation to when we received the colonies) of each pesticide combination tested, ensuring that bees came from colonies of various ages in each trial. In terms of pesticide doses used in the bioassays, our chosen insecticide and especially fungicide levels were higher than what bees likely experience in the field. Therefore, our research identifies combinations of pesticides that may pose more or less risk to bees, yet further research is necessary to elucidate if the observed results are consistent when using field-relevant doses. Furthermore, as some pesticide effects may not be immediately apparent in studies on acute toxicity, longer-term monitoring of sublethal impacts on bee health and behavior may be especially important in follow-up studies.

\subsection{Conclusions}

We show that two sterol biosynthesis inhibiting (SBI) fungicides belonging to the triazole class have synergistic effects on $B$. impatiens mortality in the presence of the neonicotinoid thiamethoxam and especially the pyrethroid bifenthrin, providing new evidence for synergistic interactions in B. impatiens. In agreement with other studies, our work highlights that even among fungicides that have the same mode of action, a high amount of variability exists in the degree of synergism they display. Importantly, we found that fenhexamid, a hydroxyanilide SBI fungicide, did not demonstrate synergistic effects on the toxicity of thiamethoxam or bifenthrin. Future work should focus on whether these results are consistent with other fungicides in this class. Our work has important implications for bee conservation and crop pollination services for two primary reasons. First, fungicides, including many SBI fungicides, are ubiquitous in agricultural landscapes and are often the most abundant pesticide compounds found in bee products (Chauzat et al. 2006; Mullin et al. 2010; McArt et al. 2017a). Second, bees are commonly exposed to potentially synergistic mixtures of fungicides and insecticides through direct exposure when foraging or through contact with hive products that retain multiple pesticides over extended periods of time (Mullin et al. 2010). These results contribute to a growing body of literature that highlights the importance of considering interactive effects when assessing pesticide risk. Although it is undoubtedly a challenge to thoroughly assess pesticide risk given the myriad potential chemical combinations to which bees are exposed in the wild, especially if considering both lethal and sublethal effects, identifying the most likely synergistic pesticide groups may streamline this process. Ultimately, determining how pesticides interact may be a crucial step in disentangling the variability in the extent to which pesticides impact bee health. 


\section{ACKNOWLEDGMENTS}

We thank Nicolas Baert, Ashley Fersch, Nelson Milano, Kerik Cox, Greg Loeb, Marvin Pritts, and Jeff Scott for their inputs on project design and implementation. We thank Nicolas Baert for conducting the LCMS/MS analysis. We thank Emma Williams for assistance with running the bioassays. We thank the Cornell Statistical Consulting Unit, particularly Erika Mudrak, for her advice on statistical procedures. We thank Louis Iverson and two anonymous reviewers for providing comments on the manuscript. We thank Koppert Biological Systems for providing bumble bee colonies at a discounted rate.

\section{AUTHORS CONTRIBUTION}

$\mathrm{AI}$ and SM conceived of the research; AI, SM, $\mathrm{CH}$, and LR designed the experiments; $\mathrm{AI}, \mathrm{CH}$, $\mathrm{LR}$, and $\mathrm{OM}$ performed experiments and analysis; all authors wrote the paper and participated in the revisions of it. All authors read and approved the final manuscript.

\section{FUNDING INFORMATION}

Funding for this project came from the National Institute of Food and Agriculture, US Department of Agriculture, grant number 2019-67013-29561 and Multistate Hatch Grant number 1010568, and from the New York Farm Viability Institute Grant number FOC 17001, each awarded to SM.

\section{COMPLIANCE WITH ETHICAL STANDARDS}

Conflict of interest The authors declare that they have no conflict of interest.

Effets synergiques de trois fongicides inhibant la biosynthèse des stérols sur la toxicité d'un insecticide pyréthroïde et néonicotinoïde chez les bourdons.

conservation des abeilles / essais biologiques / écotoxicologie / interactions pesticides / abeilles sauvages

Synergistische Effekte von drei die Sterolbiosynthese inhibierenden Fungiziden auf die Toxizität eines Pyrethroids und eines Neonikotinoids auf Hummeln.
Bienenschutz / Biotest / Ökotoxikologie / PestizidWechselwirkungen / Wildbienen

\section{REFERENCES}

Biddinger DJ, Robertson JL, Mullin C, et al (2013) Comparative toxicities and synergism of apple orchard pesticides to Apis mellifera (L.) and Osmia cornifrons (Radoszkowski). PLoS One 8:1-6. https://doi. org/10.1371/journal.pone.0072587

Champely, S. (2018) Basic functions for power analysis

Chauzat, M., Faucon, J., Martel, A., et al (2006) A survey of pesticide residues in pollen loads collected by honey bees in France 99:253-262

Cohen, J. (1988) Statistical power analysis for the behavioral sciences. Lawrence Erlbaum Associates, United States of America

Colin M-E, Belzunces LP (1992) Evidence of synergy between prochloraz and deltamethrin in Apis mellifera L.: A convenient biological approach. Pestic. Sci. 36:115119. https://doi.org/10.1002/ps.2780360206

Črešnar B, Petrič Š (2011) Cytochrome P450 enzymes in the fungal kingdom. Biochim. Biophys. Acta, Proteins Proteomics $1814: 29-35$. https://doi.org/10.1016/j. bbapap.2010.06.020

David A, Botías C, Abdul-Sada A, et al (2016) Widespread contamination of wildflower and bee-collected pollen with complex mixtures of neonicotinoids and fungicides commonly applied to crops. Environ. Int. $88: 169-178$. https://doi.org/10.1016/j.envint.2015.12.011

Fisher A, Coleman C, Hoffmann C, et al (2017) The Synergistic Effects of Almond Protection Fungicides on Honey Bee (Hymenoptera: Apidae) Forager Survival. J. Econ. Entomol. $110: 802-808$. https://doi. org/10.1093/jee/tox031

Fungicide Resistance Action Committee (2019) FRAC Code List 2019: Fungicides sorted by mode of action. 1-14. http://www.frac.info/docs/defaultsource/publications/frac-code-list/frac-code-list-2019. pdf

Garibaldi LA, Steffan-Dewenter I, Winfree R, et al (2013) Wild pollinators enhance fruit set of crops regardless of honey bee abundance. Science 339:1608-1611. https://doi.org/10.1126/science. 1230200

Glavan G, Božič J (2013) The synergy of xenobiotics in honey bee Apis mellifera: mechanisms and effects. Acta Biol Slov $56: 11-25$

Gong, Y., Diao, Q. (2017) Current knowledge of detoxification mechanisms of xenobiotic in honey bees. Ecotoxicology $26: 1-12$

Goulson D, Nicholls E, Botías C, Rotheray EL (2015) Bee declines driven by combined stress from parasites, pesticides, and lack of flowers. Science 347:1255957. https://doi.org/10.1126/science.1255957 
Greco WR, Bravo G, Parsons JC (1995) The Search For Synergy: A critical Review from a Response Surface Perspective. Pharmacol. Rev. 47:331-385

Hainzl D, Casida JE (1996) Fipronil insecticide: novel photochemical desulfinylation with retention of neurotoxicity. Proc. Natl. Acad. Sci. U. S. A. 93:12764-7. https://doi.org/10.1073/pnas.93.23.12764

Holm S (1979) A simple sequentially rejective multiple test procedure. Scand. J. Stat. 6:65-70

Huang, W. F., Solter, L. F., Yau, P. M., Imai, B. S. (2013) Nosema ceranae Escapes Fumagillin Control in Honey Bees. PLoS Pathog. 9 :(3):e1003185. https://doi. org/10.1371/journal.ppat.1003185

Insecticide Resistance Action Committee (2018) IRAC Mode of Action Classification Scheme. www.irac-online.org

Iwasa T, Motoyama N, Ambrose JT, Roe RM (2004) Mechanism for the differential toxicity of neonicotinoid insecticides in the honey bee, Apis mellifera. Crop Prot. 23:371-378. https://doi. org/10.1016/j.cropro.2003.08.018

Johnson RM, Ellis MD, Mullin CA, Frazier M (2010) Pesticides and honey bee toxicity - USA. Apidologie 41 :312-331. https://doi.org/10.1051/apido/2010018

Johnson, R. M., Dahlgren, L., Siegfried, B. D., Ellis, M. D. (2013) Acaricide, fungicide and drug interactions in honey bees (Apis mellifera). PLoS One 8 :(1):e54092. https://doi.org/10.1371/journal.pone.0054092

Kakumanu, M. L., Reeves, A. M., Anderson, T. D., et al (2016) Honey bee gut microbiome is altered by in-hive pesticide exposures Front Microbiol 7:1255. https://doi.org/10.3389/fmicb.2016.01255

Kassambara, A., Kosinski, M. (2018) survminer: Drawing survival curves using "ggplot2"

Koh I, Lonsdorf E V., Williams NM, et al (2016) Modeling the status, trends, and impacts of wild bee abundance in the United States. Proc. Natl. Acad. Sci. $113: 140$ 145. https://doi.org/10.1073/pnas.1517685113

Mao W, Schuler MA, Berenbaum MR (2017) Disruption of quercetin metabolism by fungicide affects energy production in honey bees (Apis mellifera ). Proc. Natl. Acad. Sci. 114 :2538-2543. https://doi.org/10.1073 /pnas.1614864114

Masi Biller O, Adler LS, Irwin RE, et al (2015) Possible synergistic effects of thymol and nicotine against Crithidia bombi parasitism in bumble bees. PLoS One 10 :e0144668. https://doi.org/10.1371/journal. pone. 0144668

McArt SH, Fersch AA, Milano NJ, et al (2017a) High pesticide risk to honey bees despite low focal crop pollen collection during pollination of a mass blooming crop. Sci. Rep. $7: 46554$. https://doi.org/10.1038 /srep46554

McArt, S. H., Urbanowicz, C., McCoshum, S., et al (2017b) Landscape predictors of pathogen prevalence and range contractions in US bumblebees. Proc. R. Soc. B Biol. Sci. 284 :20172181. https://doi. org/10.1098/rspb.2017.2181
Mullen, E., Wheeler, M. K., McArt, S., Cappy, P. (2017) 2016 NYS beekeeper tech team report: pesticide residues

Mullin, C. A., Frazier, M., Frazier, J. L., et al (2010) High levels of miticides and agrochemicals in North American apiaries: implications for honey bee health. PLoS One 5 (3):e9754. https://doi.org/10.1371/journal. pone. 0009754

Park, M. G., Blitzer, E. J., Gibbs, J., et al (2015) Negative effects of pesticides on wild bee communities can be buffered by landscape context Proc. R. Soc. B Biol. Sci. 282:20150299. https://doi.org/10.1098 /rspb.2015.0299

Pettis JS, Vanengelsdorp D, Johnson J, Dively G (2012) Pesticide exposure in honey bees results in increased levels of the gut pathogen Nosema. Naturwissenschaften 99 :153-158. https://doi.org/10.1007/s00114-011-0881-1

Pettis, J. S., Lichtenberg, E. M., Andree, M., et al (2013) Crop Pollination Exposes Honey Bees to Pesticides Which Alters Their Susceptibility to the Gut Pathogen Nosema ceranae. PLoS One 8 :(7):e70182. https://doi. org/10.1371/journal.pone.0070182

Pillings ED, Jepson DC (1993) Synergism between EBI fungicides and pyrethoid insecticide in the honeybee (Apis mellifera). Pestic. Sci. $39: 293-297$. https://doi. org/10.1002/ps.2780390407

R Core Team (2018) R: A language and environment for statistical computing

Raimets R, Karise R, Mänd M, et al (2017) Synergistic interactions between a variety of insecticides and an ergosterol biosynthesis inhibitor fungicide in dietary exposures of bumble bees (Bombus terrestris L.). Pest Manag. Sci. 74 :541-546. https://doi.org/10.1002 $/ \mathrm{ps} .4756$

Richardson L, Adler L, Leonard A, et al (2015) Secondary metabolites in floral nectar reduce parasite infections in bumblebees. Proc. R. Soc. B Biol. Sci. 282 :1-8. https://doi.org/10.1098/rspb.2014.2471

Robinson A, Hesketh H, Lahive E, et al (2017) Comparing bee species responses to chemical mixtures: Common response patterns? PLoS One $12: 1-21$. https://doi. org/10.1371/journal.pone.0176289

Sanchez-Bayo F, Goka K (2014) Pesticide residues and bees - a risk assessment. PLoS One 9 :e94482. https://doi.org/10.1371/journal.pone.0094482

Schmuck R, Stadler T, Schmidt HW (2003) Field relevance of a synergistic effect observed in the laboratory between an EBI fungicide and a chloronicotinyl insecticide in the honeybee (Apis mellifera L, Hymenoptera). Pest Manag. Sci. $59: 279-286$. https://doi.org/10.1002 /ps.626

Sgolastra F, Medrzycki P, Bortolotti L, et al (2016) Synergistic mortality between a neonicotinoid insecticide and an ergosterol-biosynthesis-inhibiting fungicide in three bee species. Pest Manag. Sci. 73:1236-1243. https://doi.org/10.1002/ps.4449

Thompson, H. M. (2012) Interaction between pesticides and other factors in effects on bees. EFSA Support Publ 204 . https://doi.org/10.2903/sp.efsa.2012.en-340 
Thompson HM, Fryday SL, Harkin S, Milner S (2014) Potential impacts of synergism in honeybees (Apis mellifera) of exposure to neonicotinoids and sprayed fungicides in crops. Apidologie 45:545-553. https://doi.org/10.1007/s13592-014-0273-6

Tomlin C (2009) The pesticide manual: a world compendium, 15th edn. British Crop Production Council, Alton

Tosi S, Nieh JC (2019) Lethal and sublethal synergistic effects of a new systemic pesticide, flupyradifurone (Sivantoß) on honey bees. Proc. R. Soc. B Biol. Sci. 286 :1-9. https://doi.org/10.1098/rspb.2019.0433

United States Geological Survey (2017) Estimated Annual Agricultural Pesticide Use. In: Pestic. Natl. Synth. Proj. http://water.usgs.gov/nawqa/pnsp/usage/maps/
Urbanowicz, C., Baert, N., Bluher, S. E., et al (2019) Low maize pollen collection and low pesticide risk to honey bees in heterogeneous agricultural landscapes. Apidologie 50 :379-390. https://doi.org/10.1007 /s13592-019-00655-2

Werck-Reichhart D, Feyereisen R (2000) Cytochromes P450: a success story. Genome Biol. 1:1-9. https://doi.org/10.1186/gb-2000-1-6-reviews3003

Publisher's note Springer Nature remains neutral with regard to jurisdictional claims in published maps and institutional affiliations. 